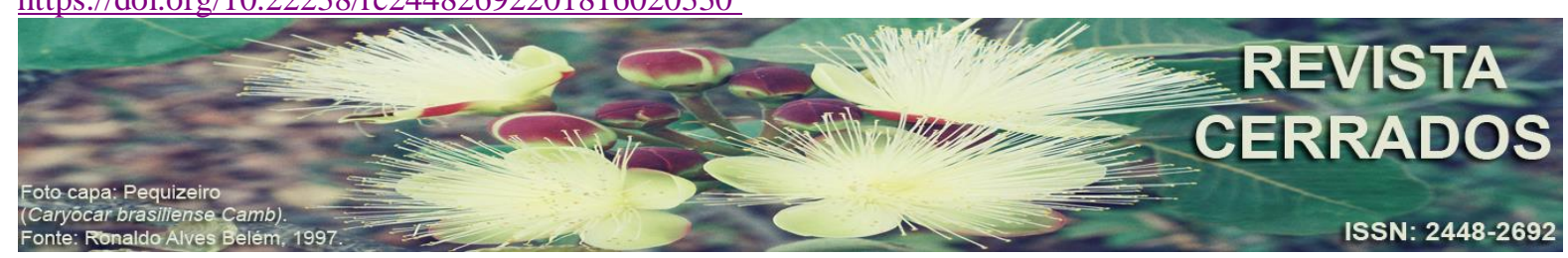

\title{
GEOGRAFIA DAS TELECOMUNICAÇÕES NO BRASIL: um esforço de síntese $^{1}$
}

\section{GEOGRAPHY OF TELECOMMUNICATIONS IN BRAZIL: an synthesis effort}

\section{GEOGRAFÍA DE LAS TELECOMUNICACIONES EN BRASIL: un esfuerzo de síntesis}

\author{
Paulo Fernando Jurado da Silva \\ Universidade Estadual de Mato Grosso do Sul - UEMS \\ E-mail: <pfjurado@uems.br>.
}

\begin{abstract}
RESUMO
A sociedade experimenta no período técnico atual transformações profundas advindas, sobretudo, do uso crescente dos serviços de telecomunicação e das tecnologias de informação que redirecionam, em diversos sentidos, os processos de acumulação, ampliação do capital, mas também das redes de articulação e gestão territorial. Em termos metodológicos e práticos, de um lado, observa-se empiricamente uma crescente incorporação das tecnologias da informação e telecomunicação na produção econômica e dos bens materiais e, de outro, se verifica a intensificação do fenômeno da desigualdade, complementaridade, antagonismo entre espaços dotados de maior densidade técnica e outros com menor carga de infraestrutura material e inovação. Assim, da mediação entre o Estado e o poder privado na utilização do território surgem conflitos, simbioses e apropriações que precisam ser mais bem estudadas na Geografia. Com isso, a análise das empresas privadas de telecomunicação é tomada como fio condutor e objetivo maior para a leitura espacial dos segmentos de televisão por assinatura, telefonia celular e internet, no momento em que o Brasil passa por diversas transformações socioespaciais, com a ampliação da densidade técnica territorial, no período recente.
\end{abstract}

Palavras-chave: Uso corporativo do território. Tecnologias da informação. Telecomunicações. Empresas de telecomunicação. Brasil.

\footnotetext{
${ }^{1}$ Este texto contém resultados da tese "Nas ondas da informação: interfaces entre o Pensamento Geográfico e a Geografia Econômica para o estudo das Telecomunicações no Brasil".
} 
SILVA, P. F. J.

Geografia das telecomunicações no Brasil: um esforço de síntese

\begin{abstract}
Society experiences, in the present technical era, deep transformations coming, mostly, from the increasing in telecommunication services and information technologies that redirect, in many ways, the accumulation process, capital enlargement, as well as the articulation nets and territorial management. In methodological and practical terms, on one side we observe a crescent incorporation of information and telecommunication technologies in the economic production and material items; on the other side we verify the intensification of the inequality, complementarity and antagonism phenomena among bigger spaces with more technical density and others with less infrastructure material and innovation. Therefore, in the mediation between the State and the private sector, in use of the territory, there are conflicts, symbiosis and appropriations that need to be better evaluated in Geography. With that, the analysis of private telecommunication companies is taken as a conduit and major objective for air space reading for cable TV, cellular phones and internet; at the moment that Brazil is going through many social air space transformations, with the expansion of technical territorial density, in the recent period.
\end{abstract}

Keywords: Corporative use of territory. Information technology. Telecommunications. Telecommunication enterprises. Brazil.

\title{
RESUMEN
}

La sociedad experimenta en el período técnico actual transformaciones profundas provenientes, sobre todo, del uso creciente de los servicios de telecomunicación y de las tecnologías de información que redireccionan, en diversos sentidos, los procesos de acumulación, ampliación del capital, pero también de las redes de articulación y gestión territorial. En términos metodológicos y prácticos, por un lado, se observa empíricamente una creciente incorporación de las tecnologías de la información y telecomunicación en la producción económica y de los bienes materiales y, por otro, se verifica la intensificación del fenómeno de la desigualdad, complementariedad, antagonismo entre espacios dotados de mayor densidad técnica y otros con menor carga de infraestructura material e innovación. Así, de la mediación entre el Estado y el poder privado en la utilización del territorio surgen conflictos, simbiosis y apropiaciones que necesitan ser mejor estudiadas en la Geografía. Con eso, el análisis de las empresas privadas de telecomunicación es tomado como hilo conductor y objetivo mayor para la lectura espacial de los segmentos de televisión por suscripción, telefonía celular e internet, en el momento en que Brasil pasa por diversas transformaciones socioespaciales, con la ampliación de la región la densidad técnica territorial, en el período reciente.

Palabras clave: Uso corporativo del territorio. Tecnologías de la información. Telecomunicaciones. Empresas de telecomunicación. Brasil.

\section{INTRODUÇÃO}

A análise das telecomunicações no Brasil revela-se em grande complexidade, no momento atual, em que as corporações ampliam o seu poder de ação no uso do território 
SILVA, P. F. J.

Geografia das telecomunicações no Brasil: um esforço de síntese

nacional de modo integrado, disponibilizando diversos serviços em conjunto aos consumidores. O mercado é concorrido e o cenário de disputa comercial é dividido entre poucos competidores (especialmente nos segmentos de televisão paga, telefonia celular e fixa), mas que apresentam vultosos lucros a cada ano, com investimentos concentrados, especialmente, nos grandes centros urbanos brasileiros, adensados em termos de população e renda.

No começo da privatização do setor de telecomunicações no Brasil, poderia se escrever, no caso da telefonia celular e fixa, que as empresas privadas agiam no território ainda de forma muito restrita e fragmentada, em termos espaciais. Isso porque o modelo de leilão restringia que os grupos consorciados operassem em mais de uma área arrematada. Isso configurava no território "lotes espaciais" de atuação das companhias, com exceção da Embratel, que operava nacionalmente, e da Intelig (empresa espelho concorrente), enquanto que a Telefónica, por exemplo, atuava no Estado de São Paulo, na estrutura do leilão, embora tivesse arrematado anteriormente operação no Rio Grande do Sul.

Adicionalmente, ficava assegurada a cada grupo consorciado uma fatia exclusiva no mercado e de caráter praticamente monopólico. Embora, haja de se ressaltar que a inserção das empresas espelho, no cenário de competição, fazia pelo menos em termos de "papel/lei" uma competição no formato de duopólio, o que não era percebida na prática pelos consumidores.

Nos anos 2000 e no início do século XXI houve uma maior liberalização para atuação no mercado por parte das companhias, o que acabou por transformar o uso do território em uma arena para disputa entre quatro grandes empresas: Vivo, Claro e Tim, decorrentes da ação do capital internacional, e do capital nacional a Oi, o que se revelou, por outro lado, na formação de um oligopólio concentrado, no plano nacional.

Sobre o período destacado, o IPEA (Instituto de Pesquisa Econômica Aplicada), em texto de discussão sobre a liberalização dos serviços de telecomunicações, produziu uma síntese das transformações societárias dessas empresas ao expor que:

A Portugal Telecom e a Telefónica de España, controladoras de diferentes empresas nas bandas A e B, se associaram na formação do grupo Vivo. A Telecom Américas, controlada pela América Móvil, passou a operar com o nome Claro. A Telecom Itália lançou a marca TIM. A Telemar e a Brasil Telecom, operadoras de telefonia fixa nas regiões I e II, adquiriram novas autorizações para exploração de telefonia móvel em suas regiões, surgindo a Oi e a Brasil Telecom Celular [...] (MIRANDA et al., 2011, p. 19). 
SILVA, P. F. J.

Geografia das telecomunicações no Brasil: um esforço de síntese

Além disso, tais companhias, depois de assumidas as metas de universalização, saem do plano de atuação meramente da telefonia fixa e celular para marcar presença fortemente nos mercados de televisão paga e internet (banda larga fixa e móvel). Em 2001, o serviço móvel celular foi transformado no serviço móvel pessoal, ampliando o poder de atuação das companhias, conectando o país gradativamente, em termos informacionais e corporativos.

Também, é a partir da leitura desse contexto que se pode escrever em termos práticos de um uso nacional do território pelas operadoras de telecomunicação, em oposição ao sentido dos lotes espaciais do passado. De 1996 a 2005 as empresas aplicaram no setor 129,2 bilhões de reais no país, atingindo o maior pico de investimento em 2001, quando as companhias se preparavam para cumprir com as metas de universalização (LOURAL; LEAL, 2010, p. 13).

Nesse caso, não se deve realizar uma análise das telecomunicações como um setor isolado dos demais da economia, mas com uma interpretação que seja capaz de relacionar a produção de conteúdos, as tecnologias da informação, as novas formas de consumo, associadas ao comércio eletrônico e por extensão a "informacionalização da economia.

Deste modo, o objetivo do artigo é avaliar, sinteticamente, as telecomunicações no país, tendo como referencial a leitura, especialmente, dos segmentos de telefonia celular, internet e televisão por assinatura, no período contemporâneo, propondo, por fim, uma regionalização a partir da compreensão do uso do território brasileiro, na perspectiva informacional. Para tanto, os procedimentos metodológicos consistiram em trabalhos de campo realizados junto as principais corporações do setor, análise das estratégias espaciais das companhias, baseada na leitura teórica e científica do assunto, bem como na busca de dados secundários a respeito e na avaliação de relatórios de investimento e nos sítios eletrônicos das empresas e na esfera pública de regulação.

Assim, o documento está organizado neste item que trata de apresentar o tema da pesquisa, procedimentos metodológicos de forma sintética e em mais três itens teóricos, sendo que os referidos abordam o uso corporativo do território pelas companhias de telecomunicações no Brasil, normatização territorial e expressão geográfica das telecomunicações, o debate sobre a forma do Psi Geográfico das telecomunicações como resultado no espaço da concentração técnica e econômica da realidade socioespacial e, por último, as considerações finais que encerram o trabalho. 
SILVA, P. F. J.

Geografia das telecomunicações no Brasil: um esforço de síntese

\section{Uso corporativo do território pelas companhias de telecomunicações no Brasil}

O movimento estratégico das companhias tem mirado em diversos sentidos e ações práticas. Com isso, são firmadas alianças entre o capital nacional e internacional para operação, em diversos momentos, na história das telecomunicações no Brasil, mas especialmente no período que acompanha a privatização e se estende até os dias atuais. Embora, haja de se fazer uma ressalva, que no segmento de televisão por assinatura já havia uma simbiose de capitais e, mais recentemente, o capital estrangeiro passa a ter o controle desse mercado de operadoras, dividindo-o basicamente em um duopólio (Claro/Net América Móvil - de um lado e de outro Sky - DirectTV Group). Enquanto que o setor de internet também contou desde o início da sua abertura na década de 1990 com investimento privado, embora em período anterior tivesse contado com maciço aporte de capital estatal e, nesse sentido, é preciso destacar que:

[...] las nuevas tecnologías impulsaron decisivamente la mundialización de todas las formas del ciclo del capital (capital-mercancía, capital-dinero, capital-productivo) estableciendo los mecanismos básicos para la progresiva transnacionalización de la economía y de la sociedad a escala planetaria (Michalet, 1985); con ello, se afirmó definitivamente el papel del capital multinacional como factor de la dinámica de acumulación. (MATTOS, 1992, p. 149).

Assim, os sócios estrangeiros têm investido cada vez mais e controlado, por sua vez, as empresas que antes tinham uma importante participação do capital nacional nas telecomunicações. Os serviços de telefonia celular, internet, televisão paga e telefonia fixa caminham no sentido das operadoras ofertarem serviços integrados em conjunto. Com isso, os clientes se tornam fidelizados às companhias e estas ganharão, por sua vez, ainda mais.

O quadro 1, por exemplo, ilustra esse cenário apresentando o ano da aprovação de leis de privatizações na América Latina, bem como o período referente à criação das respectivas agências reguladoras. Com isso, é preciso ter em mente que o Chile foi inaugurador do processo de liberalização da privatização recente, apoiando o processo de forma bastante rápida e envolvendo diversos setores da economia. Já o Brasil e o Paraguai foram os derradeiros na aprovação de leis de privatização. 
SILVA, P. F. J.

Geografia das telecomunicações no Brasil: um esforço de síntese

Quadro 1 - Aprovação da lei de privatização e criação de agência reguladora no setor de telecomunicações na América Latina.

\begin{tabular}{|l|c|c|}
\hline \multicolumn{1}{|c|}{ País } & $\begin{array}{c}\text { Ano da aprovação da } \\
\text { lei de privatização }\end{array}$ & $\begin{array}{c}\text { Ano da criação de agência } \\
\text { reguladora }\end{array}$ \\
\hline Argentina & 1990 & 1990 \\
\hline Bolívia & 1994 & 1994 \\
\hline Brasil & 1997 & 1997 \\
\hline Chile & 1982 & $1977 / 1982$ \\
\hline Colômbia & 1994 & 1994 \\
\hline República Dominicana & 1931 & 1998 \\
\hline Equador & 1993 & 1992 \\
\hline El Salvador & 1996 & 1996 \\
\hline Guatemala & 1996 & 1996 \\
\hline Honduras & 1995 & 1995 \\
\hline México & 1990 & 1995 \\
\hline Nicarágua & 1995 & 1995 \\
\hline Panamá & 1996 & 1996 \\
\hline Paraguai & 2000 & 1995 \\
\hline Peru & 1993 & 1993 \\
\hline Uruguai & 1991 & 2001 \\
\hline Venezuela & 1991 & 1991 \\
\hline
\end{tabular}

Fonte: Referenciado em Murillo (2009, p. 19) e na consulta do sítio do governo da República Oriental do Uruguai. Disponível em: <http://www.parlamento.gub.uy/leyes/AccesoTextoLey.asp?Ley=17296 \&Anchor=>. Acesso em: 13 jan. 2014. Organização: Jurado da Silva (2013).

Uma característica comum observada no plano da privatização desse grupo de países foi a formação de consórcios ou grupos de atuação para a aquisição de monopólios e espólios de empresas estatais. Mas, esta variável paulatinamente foi sendo alterada, porque parte dos grupos consorciados passou por transformações, fazendo com que houvesse um fenômeno de concentração de poder, em apenas um grupo econômico ou no máximo dois.

A divisão de operação de redes, igualmente, foi um ponto em comum quando analisada a privatização latino-americana. Assim, poderia haver a divisão do sistema de telecomunicações por diversas escalas e recortes, como por estados, interurbano, local ou mesmo internacional, dependendo do país em que foi realizada tal empreitada.

As alianças do capital nacional com o internacional igualmente devem ser mencionadas, mas a entrada de empresas como Portugal Telecom, Telefónica, Bell Canada, MCI e Telecom Itália, marcou esse cenário de disputa econômica. Ademais, a divisão em bandas A e B no início da privatização do setor de telefonia celular no país evitou inicialmente maior concorrência entre as companhias. 
SILVA, P. F. J.

Geografia das telecomunicações no Brasil: um esforço de síntese

Houve, em termos legais, a formação de um duopólio, o que na prática revelou-se em monopólio, no qual as empresas privatizadas do sistema Telebrás foram as herdeiras de amplo mercado consumidor e passaram a concentrar o mercado com maior poder de ação espacial e econômica. Antes, medidas na legislação normatizavam e impediam a entrada de um mesmo grupo em mais de uma área de concessão, mas aos poucos fusões, aquisições foram ocorrendo.

A Telebrás, nesse cenário, foi preparada institucionalmente e em termos técnicos para sua privatização, gerando uma divisão da companhia em áreas de concessão, dividindo-a, desse modo, na forma de "lotes espaciais" e o Estado brasileiro como ente regulador e demarcador de normas e da fiscalização do processo; inclusive preparando um marco regulatório antes do processo com a Lei Geral de Telecomunicações e um plano de universalização do setor. Aos investidores externos e internos, a relação de transparência foi dada, mostrando de forma clara as regras do jogo, no processo de liberalização da economia.

A concorrência passa a ser engendrada no cenário de oligopólio, em que as companhias ao se enfrentarem nacionalmente podem produzir economias de escala com a abertura de diversas alianças e estratégias, no sentido de ampliar sua gama de clientes e novos espaços de acumulação do capital, de maneira concentrada e centralizadora. Mas, é preciso destacar que a qualidade dos serviços prestados e o alcance destes à população são feitos de forma desigual. Isso porque há áreas na cidade e no campo em que o sinal tende a ser melhor em razão de fatores como a maior densidade populacional e econômica (dado o maior investimento das companhias em dotar tais locais com maior aparato técnico de redes suporte e de serviços) ou mesmo em função do relevo (barreiras geográficas).

Já há algumas cidades pequenas que não gozam, muitas vezes, de todas as companhias operando em seu território, gerando, por conseguinte, uma atuação na forma de monopólio, de modo a só ter uma única empresa a distribuir o sinal de telefonia, ou quando no máximo um duopólio. Tal realidade é constatada até mesmo em São Paulo que é o Estado brasileiro com maior Produto Interno Bruto (PIB).

Em outras palavras, enquanto o oligopólio era uma realidade no plano nacional e nos grandes centros, nos pequenos centros, interioranos, afastados das capitais e dos recursos o quadro era outro: o do monopólio ou quando no máximo duopólio. Lembrando que a temática do oligopólio, nesse caso, é de difícil generalização. Além disso, é preciso elucidar que "No mercado oligopolista a empresa determina preço e volume com base na expectativa 
SILVA, P. F. J.

Geografia das telecomunicações no Brasil: um esforço de síntese

de comportamento dos concorrentes" (SAUAIA; KALLÁS, 2007, p. 82). Por sua vez, esse quadro acaba por colocar a população em situação complicada, uma vez que os rendimentos médios auferidos pelas famílias no país não são um dos maiores no mundo, abocanhando importante fatia do total dos dispêndios efetuados pelos trabalhadores mensalmente. No estudo "Information Economy Report 2011" da ONU (Organização das Nações Unidas), por meio da UIT (União Internacional de Telecomunicações), ficou evidente essa informação ao apontar que "[...] o Brasil aparece como um dos países em desenvolvimento em que o preço da ligação de celular é o mais caro [...]"2.

Mas, há de se ressaltar que no caso dos serviços de telecomunicação no Brasil se tem uma regulação por parte do Estado que interfere no ingresso de novos concorrentes no mercado, bem como nos preços e tarifas praticadas pelos produtos e serviços ofertados, conferindo ao setor determinadas barreiras, mas que demarca nesse espaço de concorrência a participação de empresas que concentram o mercado, em termos de Market share, volume de capital investido, lucros, visibilidade na mídia e na oferta de produtos.

As táticas e estratégias de visibilidade na mídia, bem como de intervenção espacial podem ser as mais variadas possíveis, levando em conta sempre o aspecto do ganho e da ampliação do Market Share. Ademais, verificam-se entre as parcerias do grupo Globo com a Net e a Sky relações estratégicas de aliança complementar, em que esse sócio nacional investe especialmente na área de produção de conteúdo e dispõe de um leque variado de canais, enquanto as operadoras NET, Sky ficam responsáveis pela veiculação destes produtos em sua grade de canais e, nesse sentido: “As estratégias cooperativas internacionais permitem que as firmas compartilhem os riscos e recursos para entrar em mercados externos" (MELO; MUSSENGUE, 2011, p. 75).

As alianças complementares levam, portanto, em conta o "saber fazer" e o knowhow do parceiro, tendo em vista ações em conjunto que possam agregar valor para ambos sócios. Além disso, as fusões e aquisições podem servir para que uma determinada companhia possa atuar em territórios distantes com organização, recurso e ativos distintos.

Pagando a quantia de 655 milhões de dólares (35\% das ações) ${ }^{3}$, por exemplo, ao governo do Rio Grande do Sul pela CRT o grupo “[...] formado por Telefónica Internacional y sus empresas filiales Telefónica de Argentina y Compañía de Telecomunicaciones de Chile,

\footnotetext{
${ }^{2}$ Disponível em: <http://www.onu.org.br/minuto-da-telefonia-movel-no-brasil-e-um-dos-mais-caros-entrepaises-em-desenvolvimento-revela-onu/>. Acesso em: 15 fev. 2014.

${ }^{3}$ Informação referenciada em Rozas Balbontín (2005, p. 31).
} 
SILVA, P. F. J.

Geografia das telecomunicações no Brasil: um esforço de síntese

además de la empresa local Rede Brasil Sul” (ROZAS BALBONTÍN, 2005, p. 31) inaugurou o processo de abertura à iniciativa privada do setor de telefonia contemporaneamente brasileiro.

No leilão da Telebrás, a Telefónica arrematou ainda a Telesp Celular, Tele Leste Celular, Tele Sudeste Celular e a Telesp, cobrindo todo o Estado de São Paulo com o serviço de telefonia fixa e também áreas de grande densidade populacional como os Estados do Rio do Grande do Sul e Rio de Janeiro com a telefonia celular. Por fim, a companhia conseguiu alcançar as metas de universalização ao incorporar a CETERP de Ribeirão Preto, no final dos anos 90 do século XX.

No caso ainda do grupo espanhol Telefónica, observa-se que a empresa nasceu em Madrid em 1924. Mas, em meados da década de 1940, a companhia negociou suas ações com o governo espanhol que passou a ser o principal acionista da companhia, tornando-se um dos principais grupos do mundo na década de 80 do século XX (MELO; MUSSENGUE, 2011, p. 78). Depois de algum tempo a empresa passou a adquirir outras companhias no mundo, atuando na Alemanha, Reino Unido, entre outros. Nos anos 90 do século XX a companhia, controlada pelo Estado, passou para o domínio da iniciativa privada e, com isso:

[...] o processo de internacionalização da Telefônica se intensificou na década de 90, por meio de processos de aquisição de vários grupos de telefonia da América do Sul fazendo-se presente na Argentina, no Brasil, na Colômbia, no Chile, no Equador, no México, no Peru, no Uruguai, na Venezuela, além de diversos países da América Central, como a Guatemala, o Panamá, El Salvador e a Nicarágua (MELO; MUSSENGUE, 2011, p. 79).

Números do mercado consumidor, o passado colonial, semelhanças linguísticas facilitam o acesso da Telefónica a um mercado gigantesco. A empresa possui o maior número de usuários de serviços de telefonia móvel do Brasil por meio da Vivo, a segunda posição no mercado de telefonia fixa, fazendo do país o principal centro de atuação da empresa no mundo.

No passado, em 2001, a companhia incrementou seu poder no território ao se aliar com a Portugal Telecom no mercado de telefonia celular, dando origem a maior companhia de celular brasileira: a Brasicel, que é a controladora da Vivo, e que agora também atua no segmento de telefonia fixa, paga e internet, sob uma mesma marca (Vivo). O resultado desse processo normativo, financeiro, político e administrativo foi, do ponto de vista espacial e econômico, a concentração do capital e a centralização do comando pela Telefónica. 
SILVA, P. F. J.

Geografia das telecomunicações no Brasil: um esforço de síntese

No momento, a companhia oferece serviços de internet banda larga especialmente no território paulista, bem como serviço de televisão por assinatura, em algumas partes do território nacional, sendo que o grupo Portugal Telecom deixou o grupo no Brasil para se fundir posteriormente com a companhia $\mathrm{Oi}$, concentrando, evidentemente, o poder da companhia no grupo Telefónica. Outro fato relevante é o controle do provedor Terra que assegura ao grupo posição estratégica no mercado de internet no Brasil e regionalmente, na América Latina, com o investimento em diversos países.

Recentemente, a Telefónica cresceu sua participação, em termos acionários, na Telco que é controladora da Telecom Itália e, por extensão da TIM no Brasil. Assim, no momento, há no cenário de disputa entre as companhias um fato novo que, todavia, encontrase em andamento. Não se sabe qual será mais adiante o entendimento do CADE (Conselho Administrativo de Defesa da Concorrência), no Brasil, a respeito do futuro da TIM, mas, é possível que a companhia seja vendida a Claro, Oi e Vivo, em conjunto, para evitar maior concentração de mercado a favor da Vivo/Telefónica, ou mesmo que um novo grupo internacional ingresse no mercado, sendo amplos os desdobramentos prováveis desse processo.

Já outro grupo importante que disputa a liderança com a Telefónica é a Telmex/América Móvil, sendo o “[...] resultado do investimento de um grupo de mexicano que comprou participações da Sony Ericsson sediada no México [...]" (MELO; MUSSENGUE, 2011, p. 81). Já “[...] Em 1950, o mesmo grupo de mexicanos comprou participações da mexicana da ITT Corporation, tornando-se assim o único provedor de serviços telefônicos no país.” (MELO; MUSSENGUE, 2011, p. 81).

Tal companhia ainda passou para o controle do governo mexicano na década de 1970 e voltou para o controle da iniciativa privada na década de 1990 e, com isso, “[...] a TELMEX foi vendida a um grupo de investidores representados principalmente por Carlos Slim, France Telecom e Snowthwestern Bell Corporation" (MELO; MUSSENGUE, 2011, p. 81). A Telmex foi um grande player que praticamente não enfrentou concorrência no México para poder se desenvolver e tornar-se uma das maiores empresas do mundo na área de telecomunicações. No segmento de telefonia móvel a IUSA Cell era líder nos anos 1990 no México, até que desvalorização do peso mexicano e a crise financeira favoreceram com que a Telmex também ganhasse a liderança nesse segmento. 
SILVA, P. F. J.

Geografia das telecomunicações no Brasil: um esforço de síntese

A estratégia dessa companhia foi operar no segmento de baixa renda, oferecendo celular pré-pago e firmando-se como principal empresa de telefonia no México, nos anos 2000, especialmente por meio da ação da América Móvil, derivada dos investimentos dessa última. Atualmente, a companhia foca sua atuação em 18 países da América, estando presente em países como Argentina, Chile, Uruguai, México, Estados Unidos entre outros, sendo que no Brasil opera por meio da marca Claro, Embratel e Net.

A entrada do grupo se deu no Brasil por meio da compra de ações da MCI (empresa norte-americana) por 400 milhões de dólares (ROZAS BALBONTÍN, 2005, p. 25). Por meio desta ação, a empresa passou a controlar o fluxo de chamada a longa distância nacionalmente e internacionalmente.

Além disso, a aquisição das filiais antes pertencentes à BellSouth no Brasil representou o ingresso de uma das localidades mais promissoras da telefonia móvel celular no país. A região metropolitana de São Paulo foi uma dessas áreas com forte adensamento populacional e grande potencial de consumo elegida, em termos de seletividade espacial, para a atuação da empresa.

Em 2003, a companhia continuou com sua lógica de expansão territorial ao dominar a BSE S.A., que operava na região Nordeste, e o resultado foi a entrada no Rio Grande do Norte, Alagoas, Paraíba, Pernambuco, Piauí e Ceará, com uma base de clientes de 6,2 milhões (ROZAS BALBONTÍN, 2005, p. 45). Ainda nesse mesmo ano, a Telecom Américas deu início ao processo de uma ambiciosa construção de rede GSM no Estado de São Paulo, concentrando seus esforços no sentido de competir fortemente com a Vivo, no campo da telefonia móvel celular.

Porém, a companhia não parou por aí e prosseguiu seu rumo de expansão no Brasil ao comprar licenças que permitiu a esta operar em outras bandas e atingir novos territórios como Bahia, Sergipe, Paraná e Santa Catarina. Atualmente, a empresa opera em todo o território nacional, congregando esforços na área de televisão por assinatura com a Claro TV (direct to home) e por meio da NET (televisão a cabo), nos principais centros consumidores do país, a exemplo da capital São Paulo. O resultado desses esforços é o controle do mercado de televisão paga no Brasil por meio dessa companhia que é líder do segmento, seguida posteriormente pela Sky e os demais grupos.

A companhia também investiu no serviço de banda larga móvel e fixa, sendo um dos primeiros grupos no país a ingressar no serviço de tecnologia $4 \mathrm{G}$ que está presente nas 
SILVA, P. F. J.

Geografia das telecomunicações no Brasil: um esforço de síntese

principais capitais e centros do país, por meio da telefonia móvel celular da Claro. Mas, é preciso frisar que outros grupos foram crescendo, a exemplo da Telecom Itália, que por meio de subsidiária foi adquirindo diversas licenças para operar em amplos territórios, bem como as brasileiras Telemar e Brasil Telecom com a Portugal Telecom, que iriam culminar, mais adiante, na produção da Oi - Corp Co.

A Tim Participações S.A. adquiriu, por sua vez, a Intelig que é a empresa espelho que concorre diretamente com a Embratel (vinculada ao grupo mexicano de Carlos Slim). Além disso, controla a Eletropaulo Telecomunicações Ltda. e a Tim Fiber SP e Tim Fiber RJ, no segmento de fibra óptica no país.

Já o seu destino, em termos acionários no país, é indefinido, uma vez que a entrada maior da Telefónica na Telco, que controla a Telecom Itália e, por sua vez, a sua respectiva subsidiária no Brasil, provocará atenção junto aos órgãos reguladores que tomarão, em um futuro bem próximo, uma decisão acerca da condução societária da companhia no país.

Outro grupo que passa por transformações do ponto de vista de seu crescimento e atuação no mundo é a Oi, que detém investimentos na África e Ásia e que agora se soma aos investimentos da europeia Portugal Telecom, em processo de fusão.

Herdeira da Telemar e da Brasil Telecom, a companhia é líder no segmento de telefonia fixa no país e a quarta companhia em termos de Market share na telefonia móvel. Outrora, possuiu participações no provedor IG e, no momento, conta com alto investimento em barda larga fixa e móvel, bem como no mercado de televisão paga com a marca Oi TV.

Dessa forma, é possível falar de quatro grandes grupos (Vivo, Claro, Tim e Oi/CorpCo), em operação, no uso corporativo do território brasileiro, mas que se somam a empreitadas de outras empresas também bastante consolidadas e estratégicas, em seus respectivos segmentos, como na televisão por assinatura com os grupos Globo e Sky e na internet por meio de provedores com a influência do UOL (Folha de São Paulo), por exemplo.

Consequentemente, a normatização territorial da lógica do uso corporativo do território apresenta-se extremamente complexa, na qual fluxos e fixos são animados pela ação ampliada do capital privado nacional e internacional, bem como com a participação do Estado, no sentido de conferir ao território uma topologia particular, assentada na desigualdade, em termos do uso do território e pela concentração de capital e investimentos em determinadas áreas da nação do ponto de vista de uma seletividade para ação corporativa. 
SILVA, P. F. J.

Geografia das telecomunicações no Brasil: um esforço de síntese

Destarte, do ponto de vista das infraestruturas técnicas territoriais como marco da ação dos grupos apresentados e pelo papel do Estado, é possível descrever o território e a forma que ganha essa articulação do ponto de vista material e geográfico. Em outras palavras, tal ideia se concatena a tese da obra, no sentido de demonstrar, em termos geográficos, como determinados elementos definidos territorialmente interligam-se, negam-se ou mesmo se sintetizam de forma arbitrária, contraditória e desigual, levando, portanto, em última instância a propor uma área geográfica, na forma concentrada, que envolveria as metrópoles São Paulo, Rio de Janeiro, Belo Horizonte e Brasília e outra extensão o Sul do país com as regiões metropolitanas de Curitiba, Porto Alegre e em outro extremo Florianópolis e adjacência, compondo, nesse cenário, um desenho geométrico da desigualdade no território.

\section{Normatização territorial e a expressão geográfica das telecomunicações no Brasil}

O território usado como categoria para a compreensão do jogo de forças estabelecidos a partir da dinâmica corporativa das empresas de telecomunicação revela diferenciações quanto ao emprego da técnica na produção territorial e demonstra, por outro lado, aspectos da desigualdade, resultante do poder de força dos lugares, regiões e Estados. Poder este que é exercido, em grande parte, por um conjunto de agentes dominantes que reúne tanto as empresas quanto os governos.

Cada porção do território é construída e usada conforme diferentes lógicas, cabendo ao transporte e as telecomunicações a ligação de diferentes partes da estrutura territorial de um país. Sem o desenvolvimento das telecomunicações e dos transportes, o Brasil seria simplesmente um conjunto de ilhas econômicas sem ligação entre si.

Porém, hoje é preciso levar em conta que é a iniciativa privada que oferece, na maioria das vezes, tais serviços à população e, com isso, há diversas formas de cruzamento de capitais, bem como de operações e dinheiro no território. A mobilidade territorial do capital tem sido bastante elevada quando se observa as associações entre os diversos tipos de capitais, na produção desigual das corporações e na expressão geográfica dos diferentes lugares.

No Brasil, a centralização do capital tem ganhado força especialmente pela ação de grandes grupos que conformam um oligopólio, no plano nacional das telecomunicações, ao mesmo tempo em que forças locais operam territorialmente, por meio de pequenas empresas e 
SILVA, P. F. J.

Geografia das telecomunicações no Brasil: um esforço de síntese

dão ao território um significado específico. Além disso, o Estado age, nesse cenário, como regulador e, consequentemente, “[...] jurídicamente la regulación consiste en establecer reglas destinadas a disciplinar una actividad” (NALLAR, 1999, p. 116).

Não menos distante, tal terminologia advém de um processo anterior que é o da privatização e, desse modo: “[...] Privatización y regulación son conceptos que, lejos de oponerse, se complementan y coadjuvan al cumplimiento de sus fines: la privatización cuando sus efectos positivos peligran por fallas en el mercado" (NALLAR, 1999, p. 118).

As companhias usam o território corporativamente, dando a ele fixos e fluxos, a partir da regulação do Estado e de múltiplos investimentos, em diversas áreas, envolvendo filiais ao longo do globo, pontos, linhas das redes de sistemas técnicos, torres, terminais, centrais, backbones, redes de fibra óptica, satélites, data centers, entre outros. Consequentemente, o território é visto a partir de fixos, que são os pontos de emissão e recepção da informação, no processo de comunicação, mas igualmente por fluxos através da energia circulante, desprendida no processo comunicacional via cabos e satélites, conformando impulsos, ondas e sinais.

Por outro lado, é importante ressaltar que tais corporações são ainda capazes de produzir normas no território, por meio de seus dispositivos e regras de funcionamento, o que implica em padrões e princípios de conduta com os consumidores, bem como na produção e uso do território. As normatizações se ajustam territorialmente, inserindo juridicamente um conjunto de regras das quais os consumidores são signatários, por diversos contratos e práticas.

María Laura Silveira (2006), a respeito dessas articulações do mundo corporativo, destacou que: “[...] Quando as corporações encorajam, segundo várias formas de convicção, a construção das infraestruturas de que necessitam, e quando os governos decidem realizar tais obras, o processo de produção do território corporativo se fortalece [...]” (p. 95). Tornando-se mais forte, o projeto corporativo das empresas ganha território e competitividade, na busca por ampliação de lucro, bem como importância no mercado e poder.

Nesse sentido, as infraestruturas, o poder e as normas colocam-se como instrumentos eficazes, no processo de controle de determinada tecnologia, bem como no processo de gerenciamento das atividades comerciais, financeiras e técnicas, mediadas por "serviços-rede", além das "redes-suporte", na estruturação de uma determinada operação territorialmente, uma vez que, hoje mais do que nunca: “[...] os negócios governam mais que 
SILVA, P. F. J.

Geografia das telecomunicações no Brasil: um esforço de síntese

os governos (E. Daszlo, 1992) e, com a globalização da tecnologia e da economia, os Estados aparecem como servos das corporações multinacionais (R. PETRELLA, 1989) [...]" (SANTOS, 2008, p. 244).

Além disso, muitas normas são impostas por estratégias corporativas específicas, conformando um ordenamento gerencial e administrativo para instalação de infraestruturas em certa porção territorial, modernização de componentes, competição pela ampliação do lucro e avanço sobre determinado nicho comercial. Consequentemente, é preciso destacar que cada local tem, desse modo, uma densidade técnica específica, fruto da sobreposição de diferentes momentos, divisões territoriais do trabalho, da contradição entre o trabalho humano e apropriação da natureza, sendo que:

A acumulação contemporânea (Santos, 1993), encarnada nos macrossistemas técnicos, nas ações corporativas públicas e privadas e no peso das finanças e da informação, contribui para produzir uma valorização e desvalorização frenética dos pedaços do território, o agravamento da pobreza e, em definitivo, uma globalização necessária para quem comanda os processos sociais, porém desnecessário para a maior parte da sociedade. (SILVEIRA, 2006, p. 86).

Trata-se, portanto, de uma economia política do território. Tal contexto reúne tanto determinados sujeitos e agentes da produção e domínio territorial, quanto os objetos materiais construídos, apropriados e consumidos de diferentes formas pela sociedade em cada pedaço do território.

No Brasil, essa realidade é constatada por meio de corporações instaladas territorialmente que obedecem a lógicas estrangeiras, em sintonia com o desempenho de mercado de outras partes do mundo e, muitas vezes, operando em ação conjunta na vizinhança regional, isto é, na América Latina, observando que:

Firms themselves have territorial extent: the roughly bounded area over which they conduct their operations (e.g.,their market area, their labor catchment area, their supply area). For some functions of the firm the territory may be intensely local, for others it may approach the global. Such firm territories, however, are usually temporally volatile, spatially discontinuous, and not clearly bounded. Indeed, firms in competition interpenetrate each other's territories in highly complex and contested ways. (DICKEN; MALMBERG, 2001, p. 355, grifo dos autores).

Na expressão de Dicken e Malmberg (2001), as companhias acabam por possuírem uma extensão territorial própria que envolve suas operações de diferentes formas, movidas por estratégias diversificadas de negócios. Com isso, um dos grupos que têm elegido 
SILVA, P. F. J.

Geografia das telecomunicações no Brasil: um esforço de síntese

o continente americano para operação é a América Móvil, que opera no Brasil por meio da Claro, Embratel e Net. No exterior, a companhia tem focado sua atenção em quase todos os países do continente. Isso facilita, por exemplo, a eleição de estratégias corporativas e territoriais da companhia, no sentido de enxergar este mercado como um bloco que apresenta muitas semelhanças, em termos de passado histórico, étnico e econômico.

Outro grupo que também tem concentrado muito de seus esforços na América é a Telefónica, especialmente por meio da ação da Movistar em países como Argentina, Chile, Peru, Uruguai, Colômbia e Venezuela. No Brasil, a companhia opera, sobretudo, pela Vivo, mas também possui destaque na Europa e operação na China.

A Telecom Itália, por sua vez, mantém foco especialmente no Brasil (Tim), Itália e Argentina (Telecom Argentina). Mas, atua em outros mercados, a exemplo da Ásia (China e Índia), África, Europa e Oriente Médio. Já a Oi/Portugal Telecom (CorpCo) elegeu para operação áreas que, particularmente, têm a colonização portuguesa como traço comum, como é o caso do Brasil, Angola e Macau, que hoje pertence à China.

Assim, é preciso ter em vista que a eleição territorial para operação corporativa decorre de vários fatores. Nesse sentido, encontrar semelhanças nos mercados de atuação pode ser um ponto de partida para eleição da estratégia corporativa, visando uma variável facilitadora para produzir normas de gestão territorial e economia política do território comum.

O território, nessa concepção, por meio de seu uso nas telecomunicações no Brasil é resultante da ação do capital estrangeiro e nacional. Estes, por sua vez, controlam diferencialmente a ação de determinadas empresas na formação de redes de ação e estratégia corporativa, bem como nos projetos de políticas de expansão e na atuação de oligopólios, que marcam presença fortemente, em âmbito internacional.

No caso brasileiro, observa-se que as empresas que hoje são líderes em Market share, são também expressivas na América Latina, sendo o mercado comum a essas grandes corporações que se adaptam às lógicas internas de cada país para reproduzir serviços semelhantes, em toda essa extensão territorial de atuação. Lembrando que a delimitação das telecomunicações no Brasil ganha, com isso, uma lógica não somente nacional para se vincular ao mundo, por meio de uma arquitetura densa de cabos submarinos via oceano e a satélites que circulam rotineiramente a Terra, inserindo nesse contexto, o global, o nacional e o local em um plano de intersecção, em que é a escala do local por meio do lugar que 
SILVA, P. F. J.

Geografia das telecomunicações no Brasil: um esforço de síntese

acolhe/repele sintetiza esse universo contraditório, de acordo com a densidade técnica nele inserido.

Para tanto, as empresas acabam contando com Centros de Processamento de Dados, mais comumente conhecidos como Data Centers, abrigando diversos servidores e bancos de dados em quantidade e qualidade com vistas ao armazenamento, proteção e processamento de dados. Pode-se, portanto, falar de um território bem equipado, em termos técnicos de circulação e acesso à informação, vinculada às demandas do capital corporativo, e de pedaços do território em que esse tipo de informação e mensagem são vistos em outro patamar. Há, nesse sentido, um uso corporativo do território pleno em algumas partes e um uso corporativo com menor agressividade técnica e competitiva, em outras parcelas territoriais.

\section{O Psi Geográfico das Telecomunicações no Brasil}

Com isso, para representar a concentração econômica decorrente do processo de urbanização, industrialização e inserção produtiva da informação na economia no Brasil é plausível identificar no território brasileiro uma região concentrada, como escreveram Santos e Ribeiro (1979), bem como Santos e Silveira (2006). Trata-se, nesse sentido, de uma forma de regionalizar o território, sobretudo, a partir da análise da densidade técnica, científica, informacional e econômica do país, respeitando os limites municipais e os limites estaduais.

Há, entretanto, outras formas de regionalização que foram levadas a cabo por diferentes autores, como Pedro Pinchas Geiger (1969), que dividia o território em três regiões distintas com base na industrialização, aspectos naturais e nas mudanças ocorridas na urbanização daquele período, ou seja, Amazônia, Centro Sul e Nordeste. Tal regionalização não levava em conta o respeito aos limites estaduais, por exemplo, e se baseava na ideia de complexos geoeconômicos.

Nesse sentido, é preciso ter bem claro que: “As regiões também podem ser estudadas a partir de uma problemática que parta do reconhecimento daquelas funções que as inserem na atual divisão territorial do trabalho [...]" (SILVEIRA, 1999a, p. 72). Trata-se, consequentemente, de escrever sobre regiões integradas à economia internacional e outras com menor grau de inserção; regiões com forte capacidade de telecomandar e outras com menor potencial; submissas à tirania do capital e dos territórios informados corporativamente, 
SILVA, P. F. J.

Geografia das telecomunicações no Brasil: um esforço de síntese

tecnicamente, financeiramente, mecanicamente, eletronicamente, cientificamente e modernamente inovadores.

Mas, aqui como se trata de um trabalho que foca seus esforços no estudo das telecomunicações, é possível com base nas leituras e argumentações trabalhadas descrever ao menos em 7 pontos do território nacional: a presença densa de urbanização, produto interno bruno, técnica, ciência, informação, máquinas, empresas (industriais, de serviços e do comércio), mídia, provedores, empregos, carros, aviões, ferrovias e infovias. Com isso, se pode argumentar sobre uma regionalização do território nacional fundamentada no grau de: modernização tecnológica, inovação, produção industrial, importância na rede urbana e na presença plena de serviços de telecomunicações banais e complexos, que assumem as distintas economias municipais, metropolitanas e estaduais.

Para tanto, o ponto de partida para montagem conceitual de representação dessa expressão geográfica das telecomunicações no território é a abordagem areal e reticular. Com isso, a discussão areal é feita a partir da análise e seleção de determinados aglomerados urbanos e, ao mesmo tempo, reticular ao relacionar a ligação técnica material (infraestrutural) e imaterial (informacional) dessas áreas por meio de redes técnicas avançadas de fibras ópticas, data centers, satélites no ritmo da circulação de ideias em ondas; na pulsação e no movimento de um país que está em constante transformação espacial e social, ou seja, socioespacialmente. Assim, tal expressão geográfica de síntese é melhor visualizada em termos espaciais no mapa 1 .

Por conseguinte, os aglomerados elegidos para compor essa área concentrada abarcam a dimensão de cidades modernas e de um espaço rural no entorno dinâmico e técnico, para atender as demandas de uma sociedade em transformação. São, portanto, aglomerados da técnica, frutos da ciência, da informação, da urbanização, industrialização, dos serviços e do comércio avançado, em ampla relação com o plano nacional e com interações fortes com o estrangeiro. 
SILVA, P. F. J.

Geografia das telecomunicações no Brasil: um esforço de síntese

Mapa 1 - O Psi no território brasileiro.

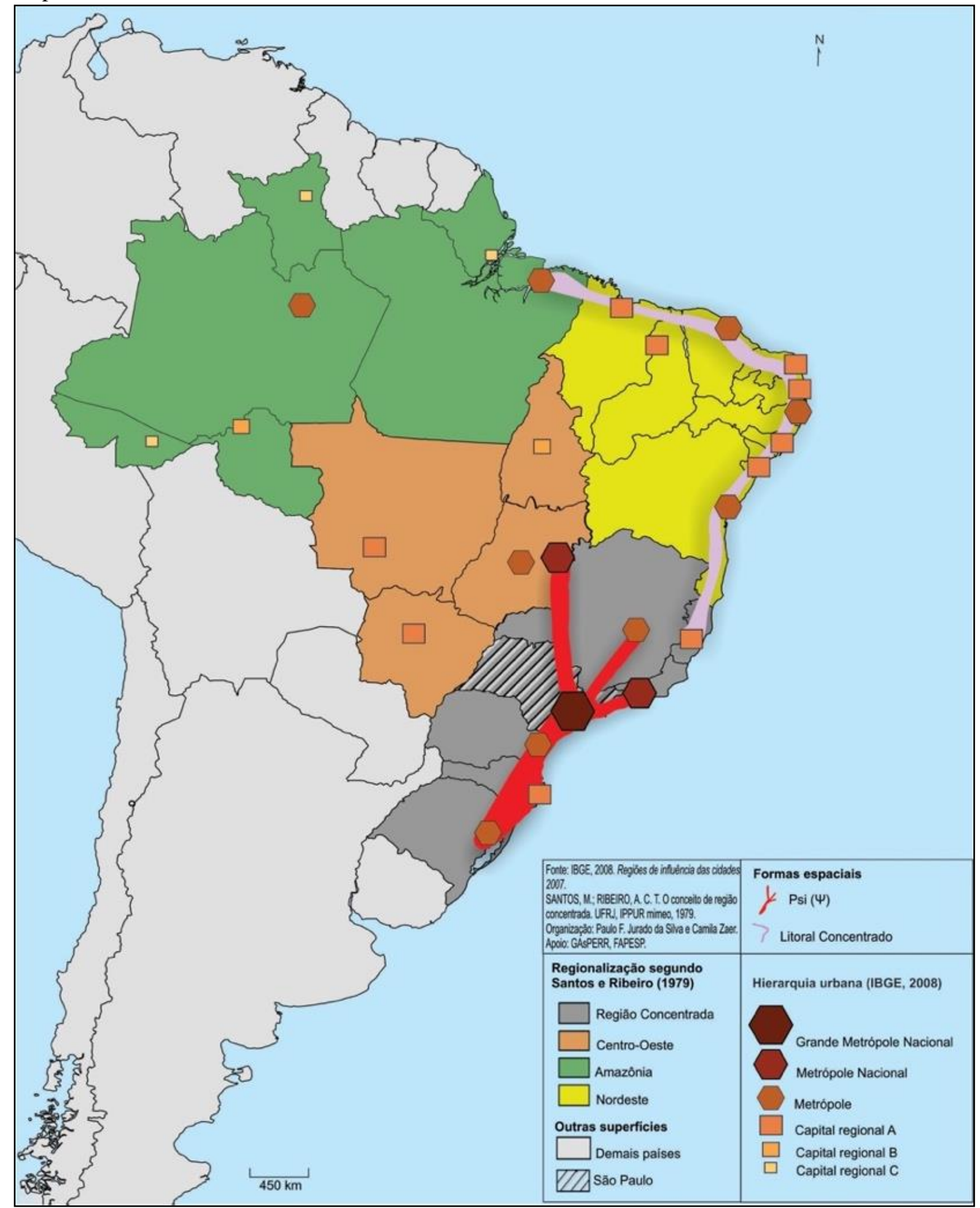

Organização: Zaer; Jurado da Silva (2014).

Nesse caso, tais espaços são, especialmente, metrópoles que coordenam uma densa rede de relações territoriais e, desse modo, apoiamo-nos, sobretudo, em Ascher para fundamentar tal cenário quando argumentou que:

Revista Cerrados, Montes Claros/MG, v.16, n. 2, p. 03-30, jul./dez.-2018. 
SILVA, P. F. J.

Geografia das telecomunicações no Brasil: um esforço de síntese

Les métropoles concentrent aussi de façon croissante les actvités stratégiques, identifiés par des fonctions (information, recherche, recherche-industrie, commerce de gros, commercial-industriel), des secteurs d'activité (presse-édition, études conseil et assistance, administration publique, recherche et enseignement supérieur, industrie, commerce interindustriel) et des professions (chefs d'entreprises, cadres, journalistes, chercheurs, ingénieurs, architectes, médecins, cadres commerciaux, etc.) [...]. (1995, p. 22).

Assim, é preciso ter em mente que não se trata de identificar somente metrópoles com função de telecomandar no território brasileiro, mas de observar, sobretudo, a proximidade em que se encontram no tecido de relações econômicas e políticas, no sentido de observar a área que possui a maior carga de densidade técnica do país e um alinhamento estratégico, na produção da normatização, regulação, circulação e gestão territorial corporativa e estatal. Por abstração genérica, denominaremos a união desses pontos de dinamicidade econômica e de forte capacidade de telecomando, resultante desse uso corporativo do território de $\Psi$ (Psi) geográfico.

Tal $\Psi$ foi eleito para representar tal fenômeno dada a sua similaridade com a forma espacial, a qual é representada no território. É, portanto, a forma espacial que ganha a articulação topológica do território das telecomunicações e do poder econômico no Brasil, como demonstra o mapa 16. Entretanto, é preciso ressaltar que se trata de um Psi imperfeito, quando analisado a continuidade territorial do fenômeno, mas que tende a se tornar mais claro quando visualizado a partir da integração imaterial que promove os serviços de telecomunicações no território, unindo essa morfologia técnica a partir de diversas redes e conformando a área que concentra maior densidade técnica e econômica do país. Nesse sentido, o Psi Geográfico da Técnica e das Telecomunicações ou Tridente da Globalização territorial seria composto por distintas unidades espaciais de telecomando, incluindo a:

Região Metropolitana de Porto Alegre (Grande Porto Alegre): inserida no Estado mais austral do país, ou seja, o Rio Grande do Sul que é a porta de entrada para o Mercosul, que reúne mercados do Cone Sul como Paraguai, Argentina e Uruguai. Mantém importante fatia da produção industrial do país, a exemplo dos segmentos químicos, universidades, centros de pesquisa e no setor de tecnologia da informação é sede permanente do Fórum Internacional Software Livre, que é um dos maiores encontros do segmento do mundo e o maior da América Latina. Nessa região, cujo tecido urbano e desenvolvimento econômico é comandado por Porto Alegre, há ainda as sedes de 
SILVA, P. F. J.

Geografia das telecomunicações no Brasil: um esforço de síntese

diversas corporações e atividades econômicas, a exemplo da produção de automóveis em Gravataí com a Chevrolet e em Guaíba com o projeto da Foton de capital chinês, voltado à produção de caminhões.

Grande Florianópolis e adjacências regionais: reunindo a área territorial da Grande Florianópolis e na adjacência a mesorregião do Itajaí (especialmente Itajaí e Blumenau) e o Nordeste de Santa Catarina (destaque para Joinville) é uma das áreas com maior industrialização do país. Florianópolis, por exemplo, apresenta diversas empresas do segmento de produção de softwares e tecnologia, contando com vários centros de tecnologia e parcerias entre universidades e empresas para a produção de tecnologias e incubadoras de negócios. Itajaí, depois de Santos, é o maior porto com movimentação de containers do Brasil, polo de produção naval e ponto de exportação de parte da indústria automobilística e têxtil nacional. Blumenau, por sua vez, destaca-se na produção metalúrgica, mecânica e elétrica, mas, sobretudo na produção de softwares, sendo a sede do Vale do Software no Sul do país, com incubadora específica na área. Já Joinville é o município com maior industrialização de Santa Catarina, com destaque para os segmentos químico, mecânico, plástico, têxtil e também a produção de softwares; e, ainda no Nordeste Catarinense há Araquari, que mesmo não sendo um grande centro, em termos demográficos, acolhe o projeto de instalação da fábrica de automóveis da BMW no Brasil.

Região metropolitana de Curitiba (Grande Curitiba): nessa porção do território paranaense estão concentrados os principais investimentos na área de inovação, centros de tecnologias e as importantes universidades do Estado. Destacam-se Araucária com a sede da REPAR (Refinaria Presidente Getúlio Vargas); São José dos Pinhais, por meio do Complexo Ayrton Senna com as montadoras da aliança RenaultNissan e também em outra extensão a Volkswagen. Já no plano da inovação, Curitiba possui diversas iniciativas, com destaque para o centro de inovação da Microsoft, no contexto da Cidade Industrial do Instituto de Tecnologia do Paraná (TECPAR) com o desenvolvimento de diversos projetos, na área de inovação e tecnologia. Além disso, encontra-se a sede do grupo Positivo Informática que é uma das maiores companhias produtoras de computadores do Brasil e a Global Village Telecom (GVT), que opera 
SILVA, P. F. J.

Geografia das telecomunicações no Brasil: um esforço de síntese

serviços de telecomunicações como internet, televisão por assinatura e telefonia, estando presente em diversas porções do território brasileiro.

Macrometrópole paulista ${ }^{4}$ : composta por um tecido urbano bastante complexo e denso é o maior polo econômico, financeiro, industrial e informacional do país. São Paulo abriga a sede de diversas grandes corporações de capital nacional e internacional em operação no Brasil; bolsa de valores; universidades com projeção internacional como a Universidade de São Paulo; centros de pesquisa; grandes grupos de comunicação como Globo São Paulo, Record, SBT e Bandeirantes; jornais de circulação nacional a exemplo de Folha de São Paulo e Estadão; provedores como UOL; operadoras de serviços de telecomunicações como a NET e Vivo. Nesse sentido, é preciso ressaltar que essa macrometrópole engloba, além da Grande São Paulo, regiões como Campinas, Baixada Santista e Vale do Paraíba e Litoral Norte. Para a Emplasa Empresa Paulista de Planejamento Metropolitano essa região é formada por “[...] 173 municípios que concentravam, em 2010, 73,3\% do total da população paulista, 83,4\% do Produto Interno Bruto (PIB) estadual e 27,6\% do PIB brasileiro -, além de abrigarem cerca de $50 \%$ da área urbanizada do Estado." 5 Nessa região, há o maior porto do Brasil, localizado em Santos, grandes refinarias como a de Paulínia, a Embraer que se dedica a produção de aviões e o Instituto Nacional de Pesquisas Espaciais (INPE) em São José dos Campos, a operadora de serviços de telecomunicações Sky em Santana do Parnaíba, o Centro de Pesquisa e Desenvolvimento em Telecomunicações (CPqD), Toyota, Honda, Samsung, Motorola, Bombardier na região de Campinas, entre tantas outras companhias reconhecidas mundialmente, seja de capital nacional ou internacional.

Região Metropolitana do Rio de Janeiro (Grande Rio): é o segundo polo econômico mais dinâmico do país, reunindo um parque industrial diversificado com refinarias de petróleo, indústria naval, petroquímicas, metalúrgica, químicas, siderúrgicas, entre

\footnotetext{
4 Designação apoiada na Emplasa - Empresa Paulista de Planejamento Metropolitano. Disponível em: <http://www.emplasa.sp.gov.br/newsletter/maio/interno/caracteristicas_objetivos.asp>. Acesso em: 14 abr. 2014.

${ }^{5}$ Citação extraída de Emplasa. Disponível em: <http://www.emplasa.sp.gov.br/newsletter/maio/interno /caracteristicas_objetivos.asp>. Acesso em: 15 abr. 2014.
} 
SILVA, P. F. J.

Geografia das telecomunicações no Brasil: um esforço de síntese

tantas outras. Tal região conta com os maiores estaleiros do país e é sede de empresas de telecomunicações como Oi e Embratel, além do maior grupo de comunicação televisiva do país: a TV Globo, que é vinculada às Organizações Globo que possuem em sua estrutura uma densa cadeia de canais de televisão paga, jornais, provedor de internet, revistas etc. Nessa região metropolitana, somam-se ainda uma lista bastante extensa de empresas importantes como Petrobras, Shell, Chevron etc. Mas, não são só empresas de capital privado, misto e estatal que garantem presença nesse território, mas também o governo e suas estruturas de administração. Assim, é o caso de citar o Banco Nacional de Desenvolvimento Econômico e Social (BNDES), Casa da Moeda do Brasil, Comissão de Valores Mobiliários (CVM), Instituto Brasileiro de Geografia e Estatística (IBGE), o Instituto Nacional da Propriedade Industrial (INPI), Eletrobrás e tantos outros órgãos, autarquias, centros de pesquisa e universidades de ponta como a Universidade Federal do Rio Janeiro.

Região Metropolitana de Belo Horizonte (Grande Belo Horizonte): inserida no contexto do Estado de Minas Gerais, possui nas atividades industriais segmentos como petroquímico, extrativo mineral, siderurgia, alimentício, metalúrgico etc. A capital Belo Horizonte, somada aos municípios de Betim e Contagem, constitui-se em um dos maiores polos econômicos do Estado, contando com a presença de diversas universidades como a Universidade Federal de Minas Gerais e centros de pesquisa. Belo Horizonte, por sua vez, está entre as capitais do Brasil com maior número populacional, PIB e área de influência. No momento, a biotecnologia, o segmento de softwares e aparelhos eletrônicos são também uma das apostas para o crescimento econômico da região metropolitana. No setor automobilístico, possui em Betim a fábrica da Fiat que atualmente é a líder de vendas no país.

Região Integrada de Desenvolvimento do Distrito Federal e Entorno: formada pela capital Brasília que abriga as sedes do executivo, legislativo e judiciário e por alguns núcleos urbanos do entorno tem na capital seu grande centro econômico, financeiro e político, sendo os centros do entorno dependentes dessa estrutura e, ao mesmo tempo, oferecendo função complementar a esta. Nelba Penna, (2003, p. 6) retratando, por exemplo, esse universo desigual e contraditório escreveu que: "Em consequência dos 
SILVA, P. F. J.

Geografia das telecomunicações no Brasil: um esforço de síntese

processos de ordenamento de seu território, ocorreu uma intensa expansão da urbanização para a periferia que deu origem à formação da região metropolitana de Brasília [...]" e, nesse sentido, a criação do “[...] chamado Entorno, atualmente institucionalizado como Região Integrada de Desenvolvimento do Distrito Federal e Entorno (RIDE)" (PENNA, 2003, p. 8). Em Brasília estão localizadas diversas sedes de estruturas governamentais, embaixadas, empresas e órgãos de representação estatal. Banco Central, Agência Nacional de Telecomunicações, Universidade de Brasília, Coordenação de Aperfeiçoamento de Pessoal de Nível Superior, Conselho Nacional de Desenvolvimento Científico e Tecnológico, Instituto Brasileiro de Informação em Ciência e Tecnologia (IBICT), diversos ministérios como o Ministério da Ciência e Tecnologia, entre tantos outros. Além disso, Brasília nos últimos anos tem investido consideravelmente no incentivo às empresas produtoras de tecnologia, desenvolvimento de software e segurança eletrônica. Isso porque a capital do país e as estruturas administrativas do governo representam um dos maiores consumidores de tecnologia da informação, com a presença do Parque Tecnológico Capital Digital, que é o Data center do Banco do Brasil e da Caixa Econômica Federal, entre tantas outras iniciativas. A Torre de TV Digital de Brasília, apelidada de "Flor do Cerrado" por Oscar Niemeyer, é também símbolo emblemático da capital que se projeta na área de telecomunicações. Brasília é, portanto, o núcleo central por onde se irradia a regulação do setor para o todo país, por meio da Anatel e do Ministério das Comunicações, e o Distrito Federal o espaço que possui maior quantidade de celulares por habitantes no Brasil, conformando a maior teledensidade do país.

Tendo em vista essa realidade plural, desigual e multifacetada é preciso reconhecer que estamos diante de universo técnico bifronte que reúne a contradição entre o moderno e o não moderno, a pobreza e a riqueza, na interface entre o ligamento e o desligamento, a inclusão e a exclusão. Nesses centros de concentração econômica e técnica não há somente riqueza do ponto de vista econômico, mas há também bolsões de pobreza, desigualdade e injustiça social.

Além disso, é válido frisar que capitais como Recife, Fortaleza, Salvador e Goiás também são relevantes para explicação do Brasil atual, desigual e complexo. Por conseguinte, determinadas capitais do Nordeste somadas a Vitória, igualmente se posicionam 
SILVA, P. F. J.

Geografia das telecomunicações no Brasil: um esforço de síntese

territorialmente de modo a desempenhar importante ação na rede urbana, bem como na concentração da técnica, sendo formas crescentes de um território em expansão, com novidades empresariais e soluções de inovação particulares. Trata-se, nitidamente de um "Litoral Concentrado", herdeiro ainda do modelo de colonização portuguesa e que com o passar do tempo foi ganhando diferentes configurações e conotações, mas, mantendo-se como espaço privilegiado para investimentos e inserção da técnica.

Já outras capitais interioranas como Cuiabá, Campo Grande Goiânia, Manaus e Belém conservam também certa concentração técnica, mas representam, sobretudo, territórios informados de conteúdo técnico e elos da ligação nacional de um país que se transforma, constantemente.

Manaus, por exemplo, localizada na região amazônica, concentra um importante polo industrial, decorrente das atividades provenientes da Zona Franca de Manaus, que criada desde 1967 e administrada pela Superintendência da Zona Franca de Manaus, reúne especialmente na produção de eletrônicos como televisões e computadores seu grande valor de mercado. Desse modo, há um território plenamente integrado às demandas do globalitarismo, do poder corporativo e do telecomando de agentes supranacionais como firmas globais e nacionais, na produção de normatizações locais.

Mas, para além do Psi ainda há a presença da informação e de densidade técnica em outras partes do território que, embora não sejam tão concentradas e dominantes, expressam uma boa parcela da realidade dos serviços de telecomunicações no país.

Nesses pedaços do território, orbitam ainda centros de polarização intermediários como Londrina, Maringá, Uberlândia, entre outros. Em centros como Londrina e Uberlândia são as empresas que foram fundadas localmente no setor de telecomunicações que possuem um papel de agir espacialmente histórico, a exemplo da Sercomtel, em Londrina, e da CTBC em Uberlândia e Triângulo Mineiro.

\section{CONSIDERAÇÕES FINAIS}

Com isso, é na dimensão das telecomunicações e da técnica no território que se configura alianças corporativas globalmente, nacionalmente e localmente. Porém, há, por outro lado, uma guerra competitiva entre distintos pedaços do território pela instalação de 
SILVA, P. F. J.

Geografia das telecomunicações no Brasil: um esforço de síntese

determinada companhia ou mesmo adoção de práticas complementares entre tais empresas e locais.

O telecomando exercido pelo Psi e também pelo oligopólio das telecomunicações no Brasil é alicerce para a construção de um controle remoto de diferentes porções do território pelo capital privado e corporativo (nacional e internacional) que reúne uma infinidade grande de companhias, setores e organismos interessados em participar da infraestrutura, dos sistemas de movimento, do uso territorial de um país com dimensões continentais, rico, diverso, mas, sobretudo desigual e carente de maior distribuição de renda, de educação, saúde e de tantos outros problemas discutidos cotidianamente nas universidades, na mídia e pela população.

Dimensões essas que deveriam compor a cidadania territorial de um país e das pessoas, pois não é o acesso a determinados serviços como telefonia celular, internet e televisão por assinatura que fazem da população mais consciente e menos alienada, pois estes são dados do consumo, do capital, do mundo das mercadorias. Com isso, a realidade é que o território foi preparado técnica e normativamente para ser instrumento de emissão e recepção das demandas da globalização e da internacionalização, em um capitalismo voltado para atender, especialmente, o poder corporativo e também as formas não solidárias de competição territorial e de amparo das estruturas de comando das classes hegemônicas.

As marcas, desse modo, entram diretamente no mundo do consumo da população como se comunicassem status, espaços são estandardizados, a televisão passa a ser o grande modelo em que se inspiram milhares de pessoas para comprar moda e objetos técnicos. Objetos esses que também são disseminados pela internet em milhares de aparelhos celulares e computadores distribuídos no território.

A partir disso, é como se a informação trouxesse à tona por meio do conjunto de serviços e redes técnicas que as suportam a promoção da globalização de um dado profundo dos valores das classes dominantes. Por isso, se fala hoje tanto em liberdade de mercados e liberdade das redes é porque o capital para se reproduzir, ainda mais, é necessário circular sem constrangimentos, barreiras espaciais e institucionais.

Por fim, são as ondas da informação de diferentes modos que transmitem a conexão e a desconexão e que ativam ou desativam lugares, compondo normatividade, ordem e poder de determinados agentes, corporações e do Estado. Os territórios são hoje, então, alvo da estratégia de grupos empresariais, da regulação estatal, do telecomando em comunicação 
SILVA, P. F. J.

Geografia das telecomunicações no Brasil: um esforço de síntese

com as grandes engrenagens que mantém o sistema capitalista em ação, por meio do poder do controle remoto corporativo dos territórios e das instituições globalmente.

\section{AGRADECIMENTOS}

Pesquisa financiada sob o processo 2011/50055-0, Fundação de Amparo à Pesquisa do Estado de São Paulo (FAPESP) e pela Coordenação de Aperfeiçoamento de Pessoal de Nível Superior (CAPES), processo 11503/12-2.

\section{REFERÊNCIAS}

ASCHER, F. Métapolis ou l'avenir des villes. Paris: Odile Jacob, 1995.

DICKEN, P.; Malmberg, A. Firms in territories: a relational perspective. Economic Geography, v. 77, n. 4, p. 345 - 363, out. 2001. Disponível em: <http://www.jstor.org/stable/3594105?origin=crossref> Acesso em: 9 ago. 2013.

LOURAL, C. A.; LEAL, R. L. V. Desafios e oportunidades do setor de telecomunicações no Brasil. Textos para discussão. Brasília: CEPAL/IPEA, 2010. Disponível em: < http://www.ipea.gov.br/portal/images/stories/PDFs/TDs/td_1545.

pdf >. Acesso em: 13 dez. 2013.

MATTOS, C. A. Nuevas estrategias empresariales y mutaciones territoriales en los procesos de reestructuración en América Latina. Revista Paraguaya de Sociología, Ano 29, n. 84, p. 145-170, 1992.

MELO, P. L. R.; MUSSENGUE, M. M. A. As atuações mexicana e espanhola no segmento de telecomunicações na América Latina. Internext - Revista Eletrônica de Negócios Internacionais da ESPM, São Paulo, v. 6, n. 2, p. 66-89, jul./dez. 2011. Disponível em: < http://internext.espm.br/index.php/internext/article/view/124> Acesso em: 10 out. 2013.

MIRANDA, P.; KUME, H.; PIANI, G. Liberalização do comércio de serviços: o caso do setor de telecomunicações no Brasil (texto para discussão 1599). Rio de Janeiro: IPEA, 2011. Disponível em:

<http://www.ipea.gov.br/portal/index.php?option=com_content\&view=article \&id=9771>. Acesso em: 18 jan. 2014.

MURILLO, M. V. Political competition, partisanship and policy making in Latin American public utilities. Nova York: Cambridge University Press, 2009.

NALLAR, D. M. El estado regulador y el nuevo mercado del servicio público. Análisis jurídico sobre la privatización, la regulación y los entes regulatorios. Buenos Aires: Depalma, 1999. 
ONU. Minuto da telefonia móvel no Brasil é um dos mais caros entre países em desenvolvimento, revela ONU. 2011. Disponível em: <http://www.onu.org.br/minuto-datelefonia- movel-no-brasil-e-um-dos-mais-caros-entre-paises-em-desenvolvimento-revelaonu/>. Acesso em: 15 fev. 2014.

PENNA, N. A. A questão urbana ambiental: política urbana e gestão da cidade. In: X ENCONTRO NACIONAL DA ANPUR, 2003, Belo Horizonte. Anais... Belo Horizonte, 2003.

ROZAS BALBONTÍN, P. Privatización, reestructuración industrial y prácticas regulatorias en el sector telecomunicaciones. Santiago: Cepal/Naciones Unidas, 2005.

SANTOS, M. A natureza do espaço: técnica e tempo, razão e emoção. 4. ed. 4. reimp. São Paulo: Edusp, 2008.

SANTOS, M.; RIBEIRO, A. C. T. O conceito de região concentrada. Universidade Federal do Rio de Janeiro, IPPUR e Departamento de Geografia, mimeo, 1979.

SANTOS, M.; SILVEIRA, M. L. O Brasil: território e sociedade no início do século XXI. 9. ed. Rio de Janeiro: Record, 2006.

SAUAIA, A. C. A.; KALLÁS, D. O dilema cooperação-competição em mercados concorrenciais: o conflito do oligopólio tratado em um jogo de empresas. Revista de Administração Contemporânea, v. 11, n. especial, p. 77-101. Disponível em: <http://www.scielo.br/scielo.php?pid=S1415-65552007000500005\&script=sci_arttext $>$. Acesso em: 16 dez. 2013.

SILVEIRA, M. L. Por uma teoria do espaço latino-americano. In: LEMOS, A. I. G.; SILVEIRA, M. L.; ARROYO, M. M. (Orgs.). Questões territoriais na América Latina. Buenos Aires: Clacso, São Paulo: Universidade de São Paulo, 2006. p. 85-100.

\section{Autor}

Paulo Fernando Jurado da Silva - Possui Graduação, Mestrado e Doutorado em Geografia pela Universidade Estadual Paulista Júlio de Mesquita Filho (UNESP), Presidente Prudente (SP). Atualmente é Gerente (Gestor) da Universidade Estadual de Mato Grosso do Sul (UEMS), Unidade Universitária de Campo Grande.

Artigo recebido em: 28 de agosto de 2018.

Artigo aceito em: 02 de outubro de 2018. Artigo publicado em: 12 de novembro de 2018. 